\title{
SARS-COV-2 and eye immunity: the lesson was learned but we are not done yet. Brainstorming on possible pathophysiology inspired by ocular models
}

\author{
Piergiorgio Neri · Massimo Lamperti - Francesco Pichi
}

Published online: 3 July 2020

(C) Springer Nature B.V. 2020

\section{Introduction}

Since its outbreak in early 2020, the novel coronavirus Severe Acute Respiratory Syndrome (SARS)-COV-2, formerly known as Covid-19, has affected more than 5 million people worldwide with a mortality rate of about $6.6 \%$, making it roughly 6 times more lethal than influenza virus [1].

Several reports have shown an eclectic attitude of SARS-COV-2, capable to affect lungs prevalently [2], but also skin [3], central nervous system [4], gastrointestinal tract [5], as well as the eye [6].

The main concern on SARS-COV-2 complications comes from lung involvement which seems to be the main reason for its high fatality rate despite prompt intervention [7], in elderly patients particularly [8]. However, many case series described young adults with a rapid and severe progression of the disease due

P. Neri $(\bowtie) \cdot$ F. Pichi

The Uveitis Service of the Eye Institute, Cleveland Clinic Abu Dhabi, Al Mariyah Island,

PO Box 112412, Abu Dhabi, UAE

e-mail: NeriP@ClevelandClinicAbuDhabi.ae

P. Neri · M. Lamperti · F. Pichi

Cleveland Clinic Lerner College of Medicine, Case

Western Reserve University, Cleveland,

$\mathrm{OH}$, USA

M. Lamperti

The Anesthesiology Institute, Cleveland Clinic Abu

Dhabi, Abu Dhabi, UAE to a massive, dramatic immune-response. Frontline physicians speculated that SARS-COV-2 might trigger either cytokine release syndrome (CRS) or its most severe manifestation called hemophagocytic lymphohistiocytosis (sHLH) [9]. sHLH is a life threatening hyperinflammatory syndrome, also known as Macrophage activation syndrome (MAS) [10], which leads to hypercytokinaemia and consequent rapid multiorgan deterioration.

Despite such a dramatic immune response, there was reluctance in using corticosteroids to prevent viral shedding [11], albeit systemic steroids were successfully used for other severe complications of viral diseases such as Herpes disease [12] and Ebola Virus disease (EVD) [13] and for central nervous system (CNS) involvement in the same SARS-COV-2 disease [14].

Recently, it was reported that dexamethasone was shown to cut deaths by one-third among patients critically ill with SARS-COV-2 [15].

Such a breaking news represent a confirmation of what anticipated by the similar viral models we reported in a previous editorial [16].

Since on label treatments are not available so far and on the basis of the concern in using systemic steroids till now, physicians started using monoclonal antibodies in order to control CRS. However, albeit the rationale behind their use appears logical and consistent, recently clinical evidences opened horizons for novel hypotheses.

The very first experimental protocol used an antiInterleukin (IL)-6 receptor monoclonal antibody 
named Tocilizumab (Actemra ${ }^{\mathrm{TM}}$, Roche Pharma (Schweiz) Ltd, B2084B21), on label for rheumatic diseases [17]. Since Tocilizumab was approved by Food and Drug Administration for the treatment of CRS secondary to chimeric antigen receptor (CAR) T-cell therapy [18], there is a rationale of using it to control the similar SARS-COV-2 related immuneresponse.

As previously reported, Zhang et al. [19] reported Tocilizumab as a rescue treatment for severe cases of SARS-COV-2 interstitial pneumonia. The promising results were followed by a number of case series which hypothesized that immune-checkpoints inhibition might play a crucial role in the control of the disease.

By recalling the experimental coronavirus retinopathy (ECOR), we hypothesized a bi-phasic nature of the disease where a direct viral insult is at the basis of the infection and later turns into a severe immune-reaction leading to a potentially massive tissue damage as observed in the ECOR model [20].

However, it remains partially unexplained why in humans SARS-COV-2 does not present always the same level of virulence.

It appears logical to speculate that specific genetics and environmental factors or specific viral triggers [21] create the conditions for a cytokine release [10]. That is the so-called "threshold model" (Fig. 1a) which makes SARS-COV-2 infection similar to the typical pathophysiology of MAS. This dramatic, multi-factorial immune reaction creates the conditions for potentially fatal complications even in young patients [22].

Despite several case series reported a certain efficacy in controlling SARS-COV-2 CRS in the following months [23, 24], Tocilizumab does not always provide an optimal response, and recent publications raised some concerns [25].

The lack of a universal response to Tocilizumab may find an explanation on a different way of acting by the immune system towards SARS-COV-2.

This may resemble some cases described in ophthalmology that did not show an optimal response to hypothetically critical immune-check points as described by Teoh et al. for chronic infantile neurological cutaneous articular (CINCA) syndrome associated uveitis [26]. The authors speculated on the paradigm of tailored treatment as a consequence of a better understanding of the polygenic nature of the inflammatory diseases, where the autoinflammation played a predominant role than autoimmunity. CINCA syndrome associated uveitis was successfully treated by an anti-IL-1 $\beta$ named Anakinra (Kineret ${ }^{\mathrm{TM}}$, Swedish Orphan Biovitrum, Stockholm, Sweden) and the authors remarked the importance of the decision making based on the disease's nature.

Similarly, Dimopoulos et al. [27] used Anakinra for the treatment of MAS in patients with severe SARSCOV-2 interstitial pneumonia [28]. The Authors based their speculations on the overproduction of IL- $1 \beta$ by tissue macrophages that may trigger secondary MAS, leading to hyper-coagulation and severe multiple organ impairment.

This evidence of a good response to anti-IL-1 $\beta$ offers different discussion ideas on the pathogenesis of the dramatic immune-response and on the reason behind fatal events occurring in young, otherwise healthy patients.

Going deeper into MAS pathophysiology, the disease is driven by genetically disrupted pathways, leading to cytokine storm syndrome. The triggers of MAS might be the following: impaired viral control, aberrant inflammasome activity, variable immune defects, as well as dysregulated metabolism [10]. The single presence or the combination of each of them might induce MAS and, consequently, threaten the life of patients.

The possible role played by inflammasome can resemble the evidence of its activity in ocular Behcet disease (BD), where the interplay between TLR2/4 and their ligands PGN/LPS leads to BD pathogenesis [29].

More specifically, the aberrant inflammasome activity might play a pivotal role both for the SARSCOV-2 related MAS and the possible occurrence in younger patient, representing the fire starter of the whole post viral immunesystem triggering.

Nucleotide-binding domain (NOD)-like receptor protein 3 inflammasome (NLRP3) is a key player for the control of viral activity. NLRP3 can recognize a series of pathogen-associated molecular patterns (PAMPs) and danger-associated molecular patterns (DAMPs) produced by viral replication, triggering antiviral immune response and facilitating viral eradication. During the rest state, level of NLRP3 is sufficiently low to avoid an abnormal inflammasome assembly and, consequently, activation. However, viral insult may trigger inflammasome activation by both viral constituents, such as RNA and PAMPs, and 


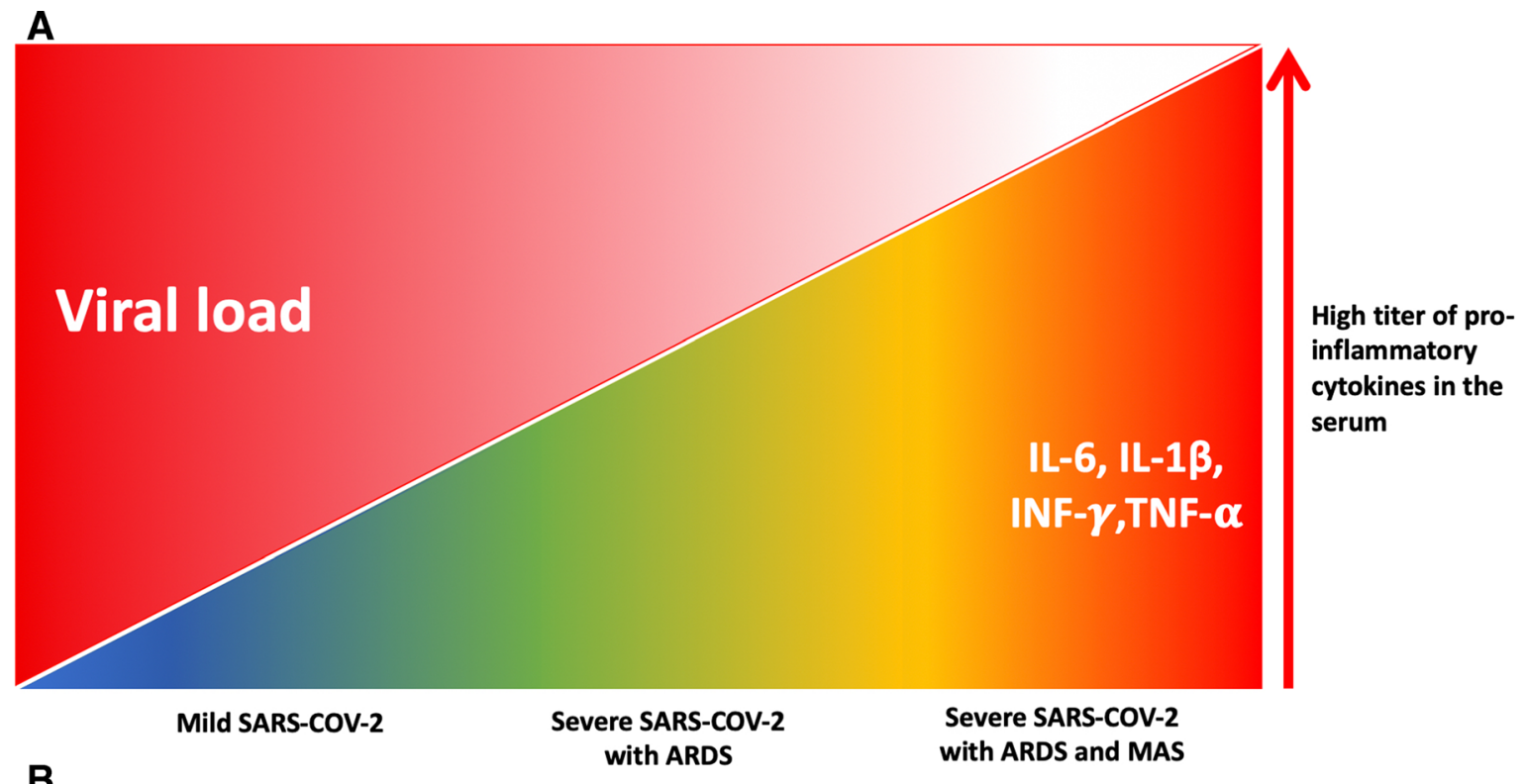

B

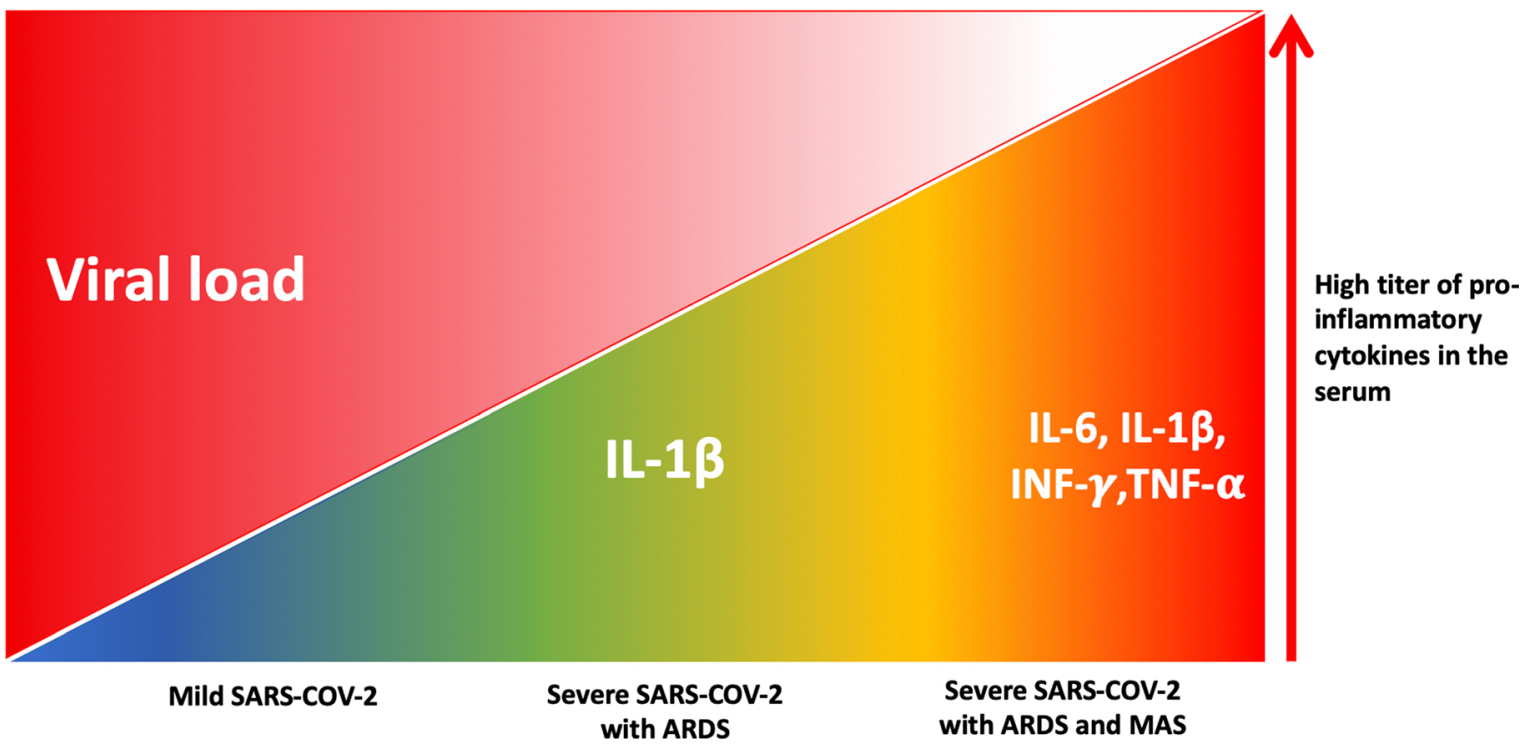

Fig. 1 a Classic "threshold model" where the viral load decrease and the role of immune-system becomes prevalent in the second phase of the disease. b Modified "threshold model" where the IL-1 $\beta$ is supposed to intervene early on and trigger the massive activation of the immune-system leading to MAC by DAMPs, such as the envelope protein of SARSCOV-2 [30]. The result NLRP3 inflammasome activation leads to IL-1 $\beta$ production [31] and induces recruitment of neutrophils in order to eliminate invading viruses [32]. In addition, IL-1 $\beta$ drives the immune-system towards the induction of adaptive immune response [30] which might be the fire starter of the second phase observed in SARS-COV-2.

At this point it is not clear why some patient affected by SARS-COV-2 have an aberrant hyper reaction to the viral insult and others don't. A hypothesis may be a possible pathogenic variant in 
the NLRP3 inflammasome genes which may enhance the risk of MAS [33]. If that speculation were true, the massive immune-response might have IL- $1 \beta$ as a key player triggering MAS induced by the SARS-COV-2 insult. Such hypothesis might be supported by the positive response to anti-IL- $1 \beta$ receptor therapy used in severe cases of SARS-COV-2 associated MAS [34].

As a direct consequence, SARS-COV-2 associated MAS seems to be closer to a secondary autoinflammatory disease than an autoimmune response.

This does not appear just a semantic difference, but it may lead to a different therapeutic approach to the disease as observed in some specific inflammatory eye diseases.

The use of anti-IL-6 receptor is not contrasting with this hypothesis. In CAR-T induced CRS, human monocytes were prevalently stimulated by both IL-1 and IL-6 and, accordingly, Tocilizumab was clinically tried and approved for its prevention. However, further studies compared Tocilizumab and Anakinra for the treatment of CRS in mouse animal model, showing lack of protection of delayed lethal neurotoxicity [35] for Tocilizumab, while Anakinra successfully controlled both CRS and neurotoxicity. In addition, it is undisputed that inflammasomes plays a primary role for IL-1 $\beta$ activation and, consequently, it may be recognized as a key factor for the induction of both CRS and MAS.

This scientific background may suggest that SARSCOV-2 associated MAS can be primarily inducted by an aberrant auto-inflammatory response, albeit a monogenic nature of the disease has not been proven yet and, most probably, it is more appropriate to consider it polygenic instead [10]. Moreover, the primary role of pyroptosis induced autoinflammation has been acknowledged, leading to the release of DAMPs, including ATP, nucleic acids and ASC oligomers [21].

In addition, the increasing number of pediatric cases of Kawasaki disease (KD) like SARS-COV-2 associated disease opens another chapter which might support such hypothesis further [36], considering that NLRP3 inflammasome has been recognized as a key player in KD pathophysiology [37].

The possible central role played by auto-inflammation in SARS-COV-2 associated MAS might change the therapeutic stepladder, or at least give more relevance to a tailored supportive immunotherapy for severe cases: an accurate study of serum cytokine profile in SARS-COV-2 patients may represent the ideal approach in order to provide a prompt and appropriate rescue treatment. Moreover, this may change the "threshold model" by putting IL- $1 \beta$ as the primary responsible for immune system triggering, and it may modify the view of the disease from a biphasic to a tri-phasic one (Fig. 1b).

The relevance of inflammasome activation and its role in SARS-COV-2 immune-reaction might be worth further investigations and may represent a perspective for the optimization of its treatment, in order to prevent life-threatening cases.

Once again, the eye might be an inspirational model: it might contribute in indicating the path in understanding SARS-COV-2 pathophysiology, as well as its treatment, and there will be more insights to come shortly for certain.

\section{References}

1. WHO (2020) Coronavirus disease 2019 (COVID-19) situation report-126. https://www.who.int/docs/defaultsource/coronaviruse/situation-reports/20200525-covid-19sitrep-126.pdf?sfvrsn=887dbd66_2

2. Vetrugno L, Bove T, Orso D et al (2020) Our Italian experience using lung ultrasound for identification, grading and serial follow-up of severity of lung involvement for management of patients with COVID-19. Echocardiography 37(4):625-627. https://doi.org/10.1111/echo.14664

3. Diotallevi F, Campanati A, Bianchelli T et al (2020) Skin involvement in SARS-CoV-2 infection: case series. J Med Virol. https://doi.org/10.1002/jmv.26012

4. Asadi-Pooya AA, Simani L (2020) Central nervous system manifestations of COVID-19: a systematic review. J Neurol Sci 413:116832. https://doi.org/10.1016/j.jns.2020.116832

5. Mao R, Qiu Y, He JS et al (2020) Manifestations and prognosis of gastrointestinal and liver involvement in patients with COVID-19: a systematic review and metaanalysis. Lancet Gastroenterol Hepatol. https://doi.org/10. 1016/S2468-1253(20)30126-6

6. Marinho PM, Marcos AAA, Romano AC et al (2020) Retinal findings in patients with COVID-19. Lancet 395(10237): 1610 . 6736(20)31014-X https://doi.org/10.1016/S0140-

7. Menter T, Haslbauer JD, Nienhold R et al (2020) Postmortem examination of COVID19 patients reveals diffuse alveolar damage with severe capillary congestion and variegated findings of lungs and other organs suggesting vascular dysfunction. Histopathology. https://doi.org/10.1111/ his. 14134

8. Liu K, Chen Y, Lin R et al (2020) Clinical features of COVID-19 in elderly patients: a comparison with young and 
middle-aged patients. J Infect 80(6):e14-e18. https://doi. org/10.1016/j.jinf.2020.03.005

9. Mehta P, McAuley DF, Brown M et al (2020) COVID-19: consider cytokine storm syndromes and immunosuppression. Lancet 395(10229):1033

10. Schulert GS, Cron RQ (2020) The genetics of macrophage activation syndrome. Genes Immun. https://doi.org/10. 1038/s41435-020-0098-4

11. Shang L, Zhao J, Hu Y et al (2020) On the use of corticosteroids for 2019-nCoV pneumonia. Lancet 395(10225):683-684

12. Stahl JP, Mailles A (2019) Herpes simplex virus encephalitis update. Curr Opin Infect Dis 32(3):239-243

13. Xu J, Tan DY, Fu YY et al (2015) Do corticosteroids have a role in treating Ebola virus disease? Sci China Life Sci 58(1):111-113

14. Pilotto A, Odolini S, Stefano Masciocchi S et al (2020) Steroid-responsive encephalitis in Covid-19 disease. Ann Neurol. https://doi.org/10.1002/ana.25783

15. Ledford H (2020) Coronavirus breakthrough: dexamethasone is first drug shown to save lives. Nature. https://doi.org/ 10.1038/d41586-020-01824-5

16. Neri P, Pichi F (2020) COVID-19 and the eye immunity: lesson learned from the past and possible new therapeutic insights. Int Ophthalmol 40(5):1057-1060. https://doi.org/ 10.1007/s10792-020-01389-2

17. Scott LJ (2017) Tocilizumab: a review in rheumatoid arthritis [published correction appears in Drugs. 2017 Dec 19]. Drugs 77(17):1865-1879. https://doi.org/10.1007/ s40265-017-0829-7

18. Wang Z, Wu Z, Liu Y et al (2017) New development in CAR-T cell therapy. J Hematol Oncol 10(1):53. https://doi. org/10.1186/s13045-017-0423-1

19. Zhang C, Wu Z, Li JW et al (2020) The cytokine release syndrome (CRS) of severe COVID-19 and Interleukin-6 receptor (IL-6R) antagonist Tocilizumab may be the key to reduce the mortality. Int J Antimicrob Agents 29:105954. https://doi.org/10.1016/j.ijantimicag.2020.105954

20. Hooper LC, Chin MS, Detrick B et al (2005) Retinal degeneration in experimental coronavirus retinopathy (ECOR) is associated with increased TNF-alpha, soluble TNFR2 and altered TNF-alpha signaling. J Neuroimmunol 166(1-2):65-74. https://doi.org/10.1016/j.jneuroim.2005. 05.018

21. Tay MZ, Poh CM, Rénia L et al (2020) The trinity of COVID-19: immunity, inflammation and intervention. Nat Rev Immunol. https://doi.org/10.1038/s41577-020-0311-8

22. Oxley TJ, Mocco J, Majidi S et al (2020) Large-vessel stroke as a presenting feature of Covid-19 in the young. N Engl J Med 382(20):e60. https://doi.org/10.1056/ NEJMc2009787

23. Toniati P, Piva S, Cattalini M et al (2020) Tocilizumab for the treatment of severe COVID-19 pneumonia with hyperinflammatory syndrome and acute respiratory failure: a single center study of 100 patients in Brescia Italy. Autoimmun Rev. https://doi.org/10.1016/j.autrev.2020. 102568

24. Xu X, Han M, Li T et al (2020) Effective treatment of severe COVID-19 patients with tocilizumab. Proc Natl Acad Sci USA 117(20):10970-10975. https://doi.org/10.1073/pnas. 2005615117
25. Radbel J, Narayanan N, Bhatt PJ (2020) Use of Tocilizumab for COVID-19-induced cytokine release syndrome: a cautionary case report. Chest S0012-3692(20):30764-9. https://doi.org/10.1016/j.chest.2020.04.024

26. Teoh SC, Sharma S, Hogan A et al (2007) Tailoring biological treatment: anakinra treatment of posterior uveitis associated with the CINCA syndrome. Br J Ophthalmol 91(2):263-264. https://doi.org/10.1136/bjo.2006.0101477

27. Dimopoulos G, de Mast Q, Markou N et al (2020) Favorable anakinra responses in severe covid-19 patients with secondary hemophagocytic lymphohistiocytosis. Cell Host Microbe. https://doi.org/10.1016/j.chom.2020.05.007

28. A trial of validation and restoration of immune dysfunction in severe infections and sepsis (PROVIDE). https:// clinicaltrials.gov/ct2/show/NCT03332225

29. Liang L, Tan X, Zhou Q et al (2013) IL-1 $\beta$ triggered by peptidoglycan and lipopolysaccharide through TLR2/4 and ROS-NLRP3 inflammasome-dependent pathways is involved in ocular Behçet's disease. Invest Ophthalmol Vis Sci 54(1):402-414. https://doi.org/10.1167/iovs.12-11047

30. Zhao C, Zhao W (2020) NLRP3 inflammasome-a key player in antiviral responses. Front Immunol 11:211. https://doi. org/10.3389/fimmu.2020.00211

31. Nieto-Torres JL, Verdia-Baguena C, Jimenez-Guardeno JM et al (2015) Severe acute respiratory syndrome coronavirus E protein transports calcium ions and activates the NLRP3 inflammasome. Virology 485:330-339. https://doi.org/10. 1016/j.virol.2015.08.010

32. Niu JL, Wu SX, Chen MK et al (2019) Hyperactivation of the NLRP3 inflammasome protects mice against influenza A virus infection via IL-1 beta mediated neutrophil recruitment. Cytokine 120:115-124. https://doi.org/10. 1016/j.cyto.2019.04.019

33. Kernan KF, Ghaloul-Gonzalez L, Shakoory B et al (2019) Adults with septic shock and extreme hyperferritinemia exhibit pathogenic immune variation. Genes Immun 20(6):520-526. https://doi.org/10.1038/s41435-018-0030-3

34. Monteagudo LA, Boothby A, Gertner E (2020) Continuous intravenous anakinra infusion to calm the cytokine storm in macrophage activation syndrome. ACR Open Rheumatol 2(5):276-282. https://doi.org/10.1002/acr2.11135

35. Norelli M, Camisa B, Barbiera G et al (2018) Monocytederived IL- 1 and IL-6 are differentially required for cytokine-release syndrome and neurotoxicity due to CAR T cells. Nat Med 24(6):739-748. https://doi.org/10.1038/ s41591-018-0036-4

36. Verdoni L, Mazza A, Gervasoni A et al (2020) An outbreak of severe Kawasaki-like disease at the Italian epicentre of the SARS-CoV-2 epidemic: an observational cohort study. Lancet. https://doi.org/10.1016/S0140-6736(20)31103-X

37. Anzai F, Watanabe S, Kimura $\mathrm{H}$ et al (2020) Crucial role of NLRP3 inflammasome in a murine model of Kawasaki disease. J Mol Cell Cardiol 138:185-196. https://doi.org/10. 1016/j.yjmcc.2019.11.158

Publisher's Note Springer Nature remains neutral with regard to jurisdictional claims in published maps and institutional affiliations. 